\title{
Estimation Of A System Model Of Regional Income Differentials \#
}

\author{
Feng-Yao Lee*
}

\section{INTRODUCTION}

American per capita personal income varies considerably from state to state. In 1950, the per capita income ratio of the lowest and highest states was only .32. Although the states with low per capita income, especially the southern states, have gained in per capita income relative to the national average, the ratio was still only .53 between the states with the lowest and highest per capita income in the nation. Among all groups of states there are marked differences in per capita income.

Income variations among state economic areas ${ }^{1}$ (SEAs) are even more substantial. The country was divided into 509 SEAs in 1960 and 510 in 1970. In 1960, the ratio between the lowest and highest SEAs' median family income was only .22 with a coefficient of variation of 24.89 , and the corresponding figures for 1970 were .30 and $20.47 .^{2}$

Many previous studies of state and regional income differentials have used "crude" statistical methodologies such as simple correlations or tabular and graphical presentations. With these methodologies there is no way of knowing whether the variables provide separate and independent explanations of income differentials. Although a few studies have used a more appropriate statistical method such as multiple regression analysis, single equation models are still not appropriate for income determination because some of the explanatory variables are interdependent with income. This joint dependence of income and explanatory variables results in biased and inconsistent estimates of the regression coefficients. Thus a simultaneous-equations model should be used in the analysis of income differentials.

The purpose of this study is to specify and estimate such a simultaneous-equations model of regional income differentials with the SEA data. ${ }^{3}$ This data set is perhaps the best yet used for such an analysis because it contains a very large number of observations on many welldefined variables for relatively homogenous areas. ${ }^{4}$ As far as can be determined, no research on income differentials has used a simultaneousequations model ${ }^{5}$ or utilized the SEA data. In addition to estimates of the

\footnotetext{
\#Thanks are due to Nguyen Huu Nghiep and Morteza Soltani-Vahid for computation and to George Choksy and anonymous referees for comments on an earlier draft. This research has been partially supported by a Faculty Fellowship from the College of Business Administration, The University of Tennessee.

*Professor of Economics, The University of Tennessee, Knoxville, TN.
} 
structural model, reduced form equations are derived to find the direct and indirect effects of the various exogenous variables on each endogenous variable.

\section{THE MODEL}

The simultaneous-equations model consists of four equations: an income equation, a total labor force participation rate equation, a female labor force participation rate equation, and a fertility rate equation.

\section{The Income Equation}

Income in this study is measured as median income of families. It is well documented that income depends directly on educational level. Family income is determined to some extent by the total labor force participation rate (Holmes and Munro 1970; Gregory, et al. 1972a). A higher labor force participation rate should increase family income because of the larger number of earners per family. Family income is also associated positively with the percentage of urban population because of the correlation between wages and the extent to which an area is urban.

Race (measured as the percentage of nonwhite population) is included as an income determinant because discrimination may reduce nonwhite income relative to white income for a given socioeconomic status (Tolley and Olson 1971). The percentage of men in the total labor force is also included for the same reason, since men, on the average, tend to hold better paying jobs or earn more than women, even if they do the same work (Nerlove and Schultz 1970). The percentage of nonwhite population is assumed to be negatively associated with income, whereas a higher percentage of men workers would be associated with a higher income. Another factor which tends to influence regional income differentials is the percentage of civilians in agriculture since incomes of farm families fall short of those earned in other occupations.

\section{The Total Labor Force Participation Rate Equation}

The total labor force participation rate is postulated to depend on the female labor force participation rate, education, unemployment and marital status.

The total labor force participation rate could be obtained as an identity from estimates of the male and female rates. However, the SEA data reveal that regional variation in the total labor force participation rate is due largely to variation in the female rate. ${ }^{6}$ This is expected because almost all men of working age work. Consequently the male labor force participation rate is more difficult to explain than the female rate (Mattila and Thompson 1968) and is thus excluded from the model. However, unemployment and marital status, which are included in the total labor force participation equation, will account for some of the variation in male rates.

Clearly, the female labor force participation rate is positively associated with the total labor force participation rate. People with more education 
will increase their expected market earnings and their opportunities to find more pleasant and interesting jobs, and thus are more eager to join the labor force. Hence the educational level should be positively associated with the labor force participation rate (Cain and Dooley 1976).

A high unemployment rate may discourage people from looking for work. On the other hand, some wives with unemployed husbands may be driven to enter the labor force due to the need for supplementary income. How unemployment rates affect total labor force participation will depend on the relative strengths of the "discouraged worker effect" and the "additional worker effect." The net relation between unemployment and labor force participation should be negative if the discouraged worker effect is stronger and should be positive if the additional worker effect predominates. The interaction of these two opposing effects could lead to insignificant association between unemployment and labor force participation.

Bowen and Finegan (1969) have found that the labor force participation of men between the ages of 25 and 54 is markedly higher for the marriedwith-wife-present group than for the other group (never married, widowed, divorced, or separated). ${ }^{7}$ On the other hand, the percentage of married women should be related negatively to the female labor force participation rate because single women are more likely than married women to have to work in order to support themselves and their dependents, and because a higher proportion of married women cannot enter the labor force because of child bearing and rearing (Nerlove and Schultz 1970). Thus the net relationship between marital status and the total labor force participation rate is not clear.

\section{The Female Labor Force Participation Rate Equation}

The female labor force participation rate is hypothesized to be a function of the fertility rate, family income, education, unemployment, race, the percent of women married, an index of demand for female labor services, and the age structure of the female population.

The fertility rate affects the female labor force participation rate negatively, since the higher the fertility rate the greater will be the number of new mothers who withdraw from the labor force for bearing and rearing their children.

Family income affects the willingness and the need of women to participate in the labor force (Nerlove and Schultz 1970). Other things being equal, the female labor force participation rate is expected to be negatively associated with family income since the theory of household behavior suggests that, if the female's freedom from the labor market is a superior good, the demand for this freedom will be higher as family income increases.

For the same reasons given earlier for the positive association between labor force participation and the educational level, the number of years of schooling completed by women is expected to exert a positive effect on 
their labor force participation rate. As was explained before, the net relation between unemployment and labor force participation is ambiguous a priori, depending on the relative strength of the discouraged and additional worker effects. This is basically an empirical issue, although there are some reasons to expect the discouraged worker effect to predominate over the additional worker effect in a cross-sectional analysis (Bowen and Finegan 1969; Mincer 1963).

The reason for the inclusion of the percentage of nonwhite population is that previous studies always showed a higher labor force participation rate for black women than for white women (Bowen and Finegan 1969; Cain 1966). The female age structure is included since an age structure with a greater percent of prime work age females will lead, other things being equal, to a higher labor force participation rate (Gregory, et al. 1972b). The reason for the negative relationship between the percentage of women married and the female labor force participation rate was stated earlier.

The female labor force participation rate of a region is clearly related to the region's employment opportunities for females. The greater the employment opportunities for females, the higher will be their labor force participation rate. Women's employment opportunities depend to a great extent on regional differences in industrial structure. From industrial structure, Nerlove and Schultz (1970) construct an index of demand for female labor services. ${ }^{8}$ The SEA data allow the derivation of such a demand index in an analogous manner as a measure of the relative abundance in the SEA of industries which tend to provide employment for women. ${ }^{9}$ This demand index is expected to relate positively to the female labor force participation rate.

Several recent studies have included wage rates of women in the female labor force participation equation. Cain and Dooley (1976) treat the wage rates as an endogenous variable in their model which consists of three equations (labor supply of married women, fertility, and wages). They acknowledged that the wage determination equation is the least satisfactory among the three equations, both theoretically and empirically; indeed, the results of the wage equation are so poor that this led them to try a two-equation model by dropping the wage equation. The wage rate was treated as an exogenous variable by Ashenfelter and Heckman (1974) and Conger and Campbell (1978). The female wage rate is not included in the simultaneous-equations models of female labor force participation used by Waite and Stolzenberg (1976) and by Smith-Lovin and Tickamyer (1978). The wage rate is not included in this study since the SEA data contain insufficient information for the derivation of wage rates. However, this exclusion is not likely to be subject to specification error, since the female wage rate largely reflects the ind ustrial structure of the area labor market (Cain and Weininger 1973), and, as was explained above, an index for the demand for female workers is included in the model of this study to measure industrial structure of the area. Also if both wage rate and industrial structure appeared as regressors in the same equation, multicollinearity might be present. 


\section{The Fertility Rate Equation}

Following the most recent fertility studies, ${ }^{10}$ the fertility rate is related to the female labor force participation rate, family income, education, and community of residence. The prices of childbearing and childrearing are expected to exert a negative effect on fertility rates. It has been asserted that the single most important price associated with childbearing and childrearing is the price or the opportunity cost of the mother's time, ${ }^{11}$ which can be imputed by participation of women in the labor force. The higher the female labor force participation, the higher is the price of a child, and the smaller family size will be desired.

Although Becker (1960) suggests that income should be positively related to fertility, many recent cross-section studies show a negative relation between income and the desired number of children. ${ }^{12}$ It is not clear $a$ priori whether income should exert a positive or negative effect on fertility in a cross-section study.

The education of parents, especially of mothers, should affect fertility negatively since the opportunity cost of child care is higher for those mothers with more education (Ben-Porath 1973), contraceptive knowledge tends to be positively associated with schooling (Michael 1973), and parents with more education may desire higher quality children (i.e., greater childrearing and schooling cost) and hence a smaller number of children (De Tray 1973).

Various population studies find that the community of residence is a major factor of disparity in fertility, mainly because of benefit-cost differentials between urban and rural areas. It is expected that the birth rate is negatively associated with the proportion of urban population and positively associated with the proportion of farm population (Phillips, et al. 1969).

Past studies of American fertility have always found a higher fertility rate for blacks than for whites, even when income, education and other social and economic factors are held constant (Grabill, et al. 1958; Kiser, et al. 1968). If income and education are included along with race in a fertility rate equation, the higher nonwhite fertility rate could be attributable to different relative prices facing nonwhites, different tastes, or greater differences between actual and desired family size for nonwhites (Gardner 1973).

In the model, the endogenous variables are family income, the total labor force participation rate, the female labor force participation rate, and the fertility rate. Other variables are treated as exogenous variables. It should be noted that treating these variables as exogenous is not always quite justified. The level of education, for instance, is a function of income and other variables and is therefore not really exogenous. It is, however, very difficult to formulate a model for education determinants; the type of income concept to be used in the education equation is not clear. This model is no exception to the general rule that the so-called exogenous variables in any model are not truly exogenous; but, any model must be closed somewhere. 


\section{ESTIMATION OF THE MODEL}

The above simultaneous-equation model in linear form was fitted to the pooled 1960 and 1970 SEA data by two-stage least-squares (2SLS) and three-stage least-squares (3SLS). Since pooled data are used, a dummy variable, 1 in 1970 and 0 in 1960, is inserted in each equation to allow a change in intercept. Because of the use of grouped data with different population size, all regressions are weighted to reflect the size of the relevant population. The weights used are: the square roots of population aged 15 to 64 for the income equation, the square roots of population aged 14 and over for the total labor force participation rate equation, the square roots of the number of women over 14 for the female labor force participation equation, and the square roots of the number of women aged 35 to 44 for the fertility rate equation. ${ }^{13}$ The variables in the structural model are defined in Table 1.

TABLE 1.

VARIABLES AND DEFINITIONS

\begin{tabular}{ll}
\hline Variable & \multicolumn{1}{c}{ Definition } \\
\hline INCOM & Median income of families, in hundreds of dollars \\
TOTLF & $\begin{array}{l}\text { The total labor force participation rate, defined as the } \\
\text { labor force (both male and female) as a percentage of total } \\
\text { population aged } 15 \text { and over }\end{array}$
\end{tabular}

EDUCA The median education level of person 25 years old and over

URBAN The percentage of urban population

RACE The percentage of nonwhite population

MENLF The percentage of men in the labor force, defined as male workers as a percentage of the total labor force (male and female over 16 in the labor force)

AGRI The percentage of civilian labor force in agriculture

FEMLF The female labor force participation rate, defined as females in the labor force as a percentage of the number of females aged 15 and over

UNEMP The unemployment rate

MARID The percentage of population 15 and over who are married with spouse present

FERT The fertility rate, defined as the number of children ever born

IDFLS The index of demand for female labor services

FEAST The female age structure defined as the percentage of the female population aged 15 and 44

DUMMY Dummy variable, 1 if 1970 and 0 if 1960 
TABLE 2.

ESTIMATES OF STRUCTURAL EQUATIONS

\begin{tabular}{|c|c|c|c|c|}
\hline \multirow{2}{*}{$\begin{array}{c}\text { Explanatory } \\
\text { Variable }\end{array}$} & \multicolumn{4}{|c|}{ Equations $^{\mathbf{a}}$} \\
\hline & INCOM & TOTLF & FEMLF & FERT \\
\hline Intercept & $\begin{array}{c}-134.662 \\
(-10.487)\end{array}$ & $\begin{array}{l}21.080 \\
(9.944)\end{array}$ & $\begin{array}{l}17.710^{\mathrm{b}} \\
(1.381)\end{array}$ & $\begin{array}{r}3720.896 \\
(32.004)\end{array}$ \\
\hline INCOM & - & - & $\begin{array}{c}-.681 \\
(-3.664)\end{array}$ & $\begin{array}{c}4.462 \\
(2.490)\end{array}$ \\
\hline TOTLF & $\begin{array}{c}1.888 \\
(11.992)\end{array}$ & - & - & - \\
\hline FEMLF & - & $\begin{array}{c}.557 \\
(10.382)\end{array}$ & - & $\begin{array}{l}-23.576 \\
(-9.233)\end{array}$ \\
\hline FERT & - & - & $\begin{array}{c}-.033 \\
(-4.505)\end{array}$ & - \\
\hline EDUCA & $\begin{array}{c}3.992 \\
(10.145)\end{array}$ & $\begin{array}{c}.880 \\
(9.128)\end{array}$ & $\begin{array}{c}4.843 \\
(3.779)\end{array}$ & $\begin{array}{c}-41.729 \\
(-2.959)\end{array}$ \\
\hline URBAN & $\begin{array}{c}.126 \\
(6.595)\end{array}$ & $\begin{array}{c}-.363 \\
(-5.610)\end{array}$ & - & $\begin{array}{c}-4.044 \\
(-6.480)\end{array}$ \\
\hline UNEMP & - & - & $\begin{array}{l}-.185^{b} \\
(-.667)\end{array}$ & - \\
\hline RACE & $\begin{array}{c}-.123 \\
(-4.344)\end{array}$ & - & $\begin{array}{c}.073^{\mathrm{b}} \\
(1.947)\end{array}$ & $\begin{array}{c}5.629 \\
(6.568)\end{array}$ \\
\hline MENLF & $\begin{array}{c}.635 \\
(5.365)\end{array}$ & - & - & - \\
\hline AGRI & $\begin{array}{c}-.445 \\
(-8.028)\end{array}$ & - & - & $\begin{array}{c}20.259 \\
(11.947)\end{array}$ \\
\hline IDFLS & - & - & $\begin{array}{c}.836 \\
(3.642)\end{array}$ & 一 \\
\hline FEAST & - & - & $\begin{array}{c}1.443 \\
(4.842)\end{array}$ & - \\
\hline MARID & - & $\begin{array}{c}.100 \\
(3.923)\end{array}$ & $\begin{array}{c}-.810 \\
(-4.083)\end{array}$ & - \\
\hline DUMMY & $\begin{array}{c}31.873 \\
(39.991)\end{array}$ & $\begin{array}{c}-2.204 \\
(-10.054)\end{array}$ & $\begin{array}{l}40.711 \\
(4.484)\end{array}$ & $\begin{array}{c}595.690 \\
(10.049)\end{array}$ \\
\hline
\end{tabular}

${ }^{\mathrm{a}}$ The figures in parentheses under estimated coefficients are their $t$-values.

${ }^{\mathrm{b}}$ Indicates that the coefficient is not significant at the five percent level. 
The structural coefficients estimated by 2SLS and 3SLS were quite similar; the estimates obtained by the two methods all had identical signs and were approximately of the same magnitude in most cases. Although 3SLS yielded smaller standard errors of estimates than 2SLS as expected, the improvement in efficiency of the 3SLS over the 2SLS was very limited. Thus only the 2SLS estimates of the structural equations are reported in Table $2 .{ }^{14}$

The results in Table 2 conform well to a priori expectations. All coefficients in the model carry signs confirming the theoretical arguments made earlier; and are significant at the .05 probability level except for unemployment and race coefficients in the female labor force participation rate equation.

A remaining question concerns whether it is appropriate to use money or real income in the analysis. Since cost of living differs from region to region, it may be argued that real income (i.e., money income deflated by cost of living index) should be used. However, no such index is available to show the differences in cost of living among the 510 SEAs. ${ }^{15}$ Moreover, since the primary purpose of this study is to quantify the effects of various variables on regional income and not the effect of income on other variables, money income is the more relevant variable. All other studies of regional income differentials used money income. ${ }^{16}$ Consequently, the analysis is based on money income.

\section{MULTIPLIER ANALYSIS}

The above structural coefficients measure only the direct effect, since they are partial derivatives (i.e., the derivatives derived by holding all other exogenous and endogenous variables constant). In order to measure the magnitude of the direct and indirect impacts of the exogenous variables on the endogenous variables, the reduced-form equations are derived from the 2SLS estimates of the above structural model such that each endogenous variable is expressed as a function of all exogenous variables. ${ }^{17}$

In order to compare the relative magnitudes of the influences of various exogenous variables on the endogenous variables, the elasticity multipliers are computed at the sample means from the derived reduced form coefficients or multipliers and are presented in Table 3. The elasticity multiplier measures the percentage change in the endogenous variable due to a given percentage change in an exogenous variable (i.e., the multiplier of the endogenous variable with respect to the exogenous variable divided by the ratio of the mean endogenous to the mean exogenous) when the direct and indirect influences of the exogenous variable are taken into account. Thus in Table 3, the income elasticity multiplier of 1.140 with respect to education means that if both the direct and indirect impacts of the educational level are considered, then a one percent increase in the educational level would result in an increase of 1.140 percent in income.

In the income equation, the large positive impacts that education and the index of demand for female labor services have on income are in accord with a priori expectations. The female age structure and the percent 
of women married also have fairly large effects on income. The percent of urban population and the percent of men in the labor force have positive effects and the percent of labor force in agriculture has a negative effect on income as expected, although the magnitudes of their effects are quite small. The magnitudes of the elasticity multipliers for race and the unemployment rate are negligible. While the education elasticity multiplier is 1.140 , the education elasticity computed from the estimated structural model is only .670. The sum of the direct and the indirect impacts of education on income is nearly twice as large as the direct effect alone. This is due largely to the negative impact of education on fertility and its positive impact on female labor force participation; the fertility rate associates negatively with the female labor force participation rate, which affects positively the total labor force participation rate, which in turn has a positive impact on income.

In the other three equations, the index of demand for female labor services has the largest effect, especially on the female labor force participation rate. The female age structure and the percent of women married also have large impacts, especially in the female labor force participation equation. Education and the percent of men in the labor force have fairly large direct and indirect impacts on the total and female labor force participation rates. The elasticity multipliers of other exogenous variables are minimal.

\section{COMPARISON WITH OTHER STUDIES}

A few studies have analyzed regional income differentials in the U.S. at the national level using ordinary least-squares method to estimate single income equation models. They provide no indirect effects of explanatory variables on income. Nevertheless some of the estimates of these studies

TABLE 3 .

ELASTICITY MULTIPLIERS OF ENDOGENOUS VARIABLES WITH RESPECT TO EXOGENOUS VARIABLES*

\begin{tabular}{|c|c|c|c|c|c|c|c|c|}
\hline & & UR & UN & F. & $\mathrm{F}$ & AGRI & ID & AST M \\
\hline M & & .12 & 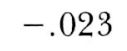 & -.021 & .126 & 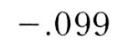 & 1.224 & .812 \\
\hline OTLF & .335 & .01 & - & 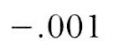 & - . & & 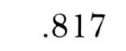 & .542 \\
\hline EMLF & .421 & .041 & .048 & .003 & -.881 & & 2.179 & $4-1.520$ \\
\hline ERT & -.151 & -.072 & -.016 & .018 & .256 & .070 & & .354 \\
\hline \multicolumn{9}{|c|}{ *The derived reduced form equations are given below: } \\
\hline NCOM $=$ & \multicolumn{8}{|c|}{$\begin{aligned}= & -120.369+7.132 \text { EDUCA }+.154 \text { URBAN }-.317 \text { UNEMP }-.133 \text { RACE }+.129 \text { MENLF }-.734 \text { AGRI } \\
& +.804 \text { IDFLS + } 1.388 \text { FEAST }-.741 \text { MARID + 25.885 DUMMY; }\end{aligned}$} \\
\hline OTLF $=$ & \multicolumn{8}{|c|}{$\begin{aligned}= & 7.570+1.663 \text { EDUCA }+.015 \text { URBAN }-.168 \text { UNEMP }-.005 \text { RACE }-.268 \text { MENLF }-.153 \text { AGRI } \\
& +.426 \text { IDFLS + } .735 \text { FEAST }-.392 \text { MARID }-3.171 \text { DUMMY; }\end{aligned}$} \\
\hline FEMLF & \multicolumn{8}{|c|}{$\begin{aligned}= & -24.254+1.407 \text { EDUCA }+.027 \text { URBAN }+.350 \text { UNEMP }-.009 \text { RACE }-.481 \text { MENLF }-.274 \text { AGRI } \\
& +.764 \text { IDFLS + } 1.320 \text { FEAST }-.884 \text { MARID }-1.737 \text { DUMMY; }\end{aligned}$} \\
\hline ERT & \multicolumn{8}{|c|}{$\begin{aligned}= & 3755.630-43.068 \text { EDUCA }-3.984 \text { URBAN }-9.688 \text { UNEMP + } 5.268 \text { RACE + } 11.920 \text { MENLF } \\
& +23.456 \text { AGRI }-14.444 \text { IDFLS }-24.931 \text { FEAST + 17.538 MARID + 752.149 DUMMY. }\end{aligned}$} \\
\hline
\end{tabular}


can be compared roughly with the estimate of the structural income equation presented in Table 2.

Using the 1940 data, Fulmer (1950) estimated a linear regression of state per capita income on four variables (percent of labor force in agriculture, percent of total black population, percent of total population employed, and median years of schooling of all males 25 years of age or over) and found all regression coefficients highly significant. His regression coefficients have identical signs to the corresponding coefficients given in Table 2 , and are very much smaller in magnitudes as expected, since income in 1940 was at a much lower level than in 1960 and 1970. An increase of one year of education, for example, resulted in an increase of $\$ 56$ in 1940, and $\$ 399$ in 1960-1970, and a decrease of 10 percentage points in the percent of the labor force in agriculture was associated with a $\$ 50$ increase in income in 1940 and $\$ 445$ in 1960-1970.

Using the 1960 data of 135 SMSA's, Mattila and Thompson (1968) regressed median family income on percent of population with less than six years of education, the percent of adult population completing four or more years of college, the male labor force participation rate, population of the SMSA (in logarithm), the percent of total employment engaged in manufacturing, the capital to labor ratio, the degree of specialization in durables, foreign born as a percent of total population, and the percent of labor force self-employed. The problem associated with the comparison of their estimated equation with the income equation in Table 2 is that the two equations differ in specification and, except for the dependent variable, none of the variables in the two equations are identically defined. Only the first four of their explanatory variables are somewhat relevant to this study. Their estimate indicates that a decrease of one percentage point in the first variable and an increase of one percentage point in the second and third variables were associated respectively with an increase in income of $\$ 58, \$ 81$, and $\$ 41$, and the coefficient of the logarithm of area population was 272. The effect of the male labor force participation rate seems too small as compared with the TOTLF effect of $\$ 189$ derived from the pooled 1960 and 1970 data in this study. Although both studies show the positive effect of education on income, it is difficult to compare the magnitudes of the effect because the education variable was quite differently defined. In this study, an increase of 10 percentage points in the percent of urban population would raise income by $\$ 126$. Although it is inappropriate to compare the magnitude of this effect with that of population effect, the positive effects of both urban and population size are in accord with expectations. ${ }^{18}$

\section{CONCLUSIONS}

To the extent that the data permit, the structural model is believed to be well specified. All estimated structural coefficients are in accord with expected signs and nearly all coefficients are statistically significant at the five percent level.

Although the total labor force participation rate and the percent of men in the labor force have larger elasticities than other variables in the income 
structural equation, ${ }^{19}$ the magnitudes of their elasticities become very much smaller when the indirect impact is also taken into account. Income elasticities of education computed from the structural equation are fairly large, and the magnitudes of the elasticities almost double when the indirect effect is also included. The percent of urban population has a relatively small direct impact on income, and its indirect impact is even smaller. The direct and indirect impacts of race and the percent of the labor force in agriculture on income are negligible. Perhaps the most effective policies to increase family income are those which would raise the educational level as well as the female labor force participation rate; the latter could be effected greatly by increasing the employment opportunities of women.

\section{FOOTNOTES}

${ }^{1} \mathrm{~A}$ SEA is defined as a single county or a group of contiguous counties within a given state which has similar economic and social characteristics.

${ }^{2}$ In 1960 median family incomes were 1,879 and 8,392 for the lowest and highest SEAs with standard deviation of 1,228. In 1970 the lowest and highest SEAs had median family incomes of 5,597 and 16,604 with standard deviation of 1,844 . In terms of both mean family income and per capita income, the ratio of the lowest and highest SEAs' incomes was .33 with a coefficient of variation of 19. Note that mean family income and per capita income are not available in the 1960 SEA data.

${ }^{3}$ The data were derived from U.S. Department of Commerce, Bureau of the Census, State Economic Areas, United States Government Printing Office, 1962 and 1972.

${ }^{4}$ SEAs are relatively homogenous subdivisions of states since the boundaries of these areas have been drawn in such a way that each state is subdivided into relatively few parts, with each part having certain significant characteristics which distinguish it from adjoining areas.

${ }^{5}$ The only exception is R. A. Holmes and J. M. Munro (1970), which analyzed regional differences in income levels and income distribution in Canada. The specification of their simultaneous-equations model is markedly different from that of this study.

${ }^{6}$ The coefficient of variation for labor force participation is 8.7 for males and 17.1 for females in the pooled 1960 and 1970 data.

${ }^{7}$ They have given a few reasons for this association between marital status and male labor force participation. A man who elects to marry and stay married has a more stable personality, which also shows up in his ability to keep a job. With marriage come finnncial respr. sibilities that serve as a strong incentive to labor force participation. Besides, in order to avoid scorn shown by family and friends to a husband who dares to loaf, a married man would rather be in the labor force. Furthermore, men who prefer to lead a free and easy life may choose to stay single and thus be free from the marital nagging the married men encounter.

${ }^{8}$ Bowen and Finegan (1969) also construct such a demand variable similarly in their study of married women labor force participation.

${ }^{9}$ In SEA files, industry was classified into 10 groups in 1970 and 14 groups in 1960.

${ }^{10}$ Notable among these are Esterlin (1969), Schultz (1969), Nerlove and Schultz (1970), Gregory, et al. (1972a, 1972b) and Conger and Campbell (1978).
${ }^{11}$ See, for instance, Cain (1971).

${ }^{12}$ Several reasons have been given to explain why Becker's theoretical expectation of a positive relation between income and fertility often fails to show up in a single cross-section analysis. It is argued that expected or permanent income should be used instead of current or measured income since the latter concept of income is not as relevant as the former to household decisions. The price of child care varies by income level, and if the price rises sufficiently high with income, higher incomes may result in smaller numbers of desired children. Parents with higher income may increase the demand for quality relative to quantity of children, and to have higher quality children (at a higher cost per child), the parents will have a smaller quantity. The knowledge and practice of birth control might be associated positively with income.

${ }^{13}$ The fertility rate used in this study is the completed cohort fertility, i.e., the number of children born to women by the end of their childbearing ages (between 35 and 44). Note that square roots are used as weights to improve the efficiency of the estimates.

${ }^{14}$ Since 3SLS incorporates all of the available information in the entire system into its estimates, the estimates of all the structural parameters are affected rather than only the estimates of the structural parameters of one equation if the model is misspecified. 2SLS is a singleequation method which only utilizes knowledge of the zero restrictions in the particular equation being estimated and thus its estimates are not affected by the misspecification of other equations in the system. Moreover, Monte Carlo studies have shown that 2SLS estimates are much less sensitive than 3SLS estimates to the presence of multicollinearity and specification errors. Thus, 2SLS estimates are chosen over 3SLS estimates. The results for 3SLS are available from the author on request.

${ }^{15}$ The data which can be used to measure the best approximation of living cost differentials among the SEAs are the indexes of comparative costs for an urban family of four by the Bureau of Labor Statistics. Real income was obtained by deflating the money income by the index of comparative budget based on a moderate living standard. 2SLS estimates of the structural equations with real income were obtained and the results are available from the author. When real income was used, the URBAN coefficient in the INCOM equation became negligible and was much smaller than its standard error. Other than this, there was not much difference between the estimates based on money income and those based 
on real income. The problem associated with the use of real income is that the derivation of real income does not reflect fully and accurately the regional differentials in living cost.

${ }^{16}$ See, for instance, Fulmer (1950), Hanna (1959), Booth (1964), Mattila and Thompson (1968), and Holmes and Munro (1970).

${ }^{17}$ Since a reduced-form coefficient or multiplier of an exogenous variable is the total partial derivative (i.e., the derivative obtained with the other exogenous variables unchanged but with the endogenous variables adjusting to their new equilibrium), it measures the total direct and indirect effects of the exogenous variable on the endogenous variable.

${ }^{18}$ The percent of urban population in an SEA is highly positively correlated with the population size of an SMSA; an SEA containing a large SMSA has a higher percent of urban population.

${ }^{19}$ Income elasticities of the total labor force participation rate and the percent of men in the labor force computed from the structural income equation are 1.497 and .621 , respectively.

\section{REFERENCES}

Ashenfelter, Orley and Heckman, James, "The Estimation of Income and Substitution Effects in a Model of Family Labor Supply," Econometrica, 42:73-85 (1974).

Becker, Gary S., "An Economic Analysis of Fertility," in Universities National Bureau Committee for Economic Research, Demographic and Economic Change in Developed Countries. Princeton, N.J.: Princeton University Press, 1960

Ben-Porath, Yorman, "Economic Analysis of Fertility in Israel: Points and Counterpoints," Journal of Political Economy, 81:Part II, 70-95 (1973).

Booth, E. J. R., "Interregional Income Differences," Southern Economic Journal, 30:44-51 (1964).

Cain, Glen G., Married Women in the Labor Force. Chicago: Chicago University Press, 1966.

"Issues in the Economic Theory of a Population Policy for the United States," American Economic Review, Papers and Proceedings, 408-417 (1971)

and Dooley, Martin D., "Estimation of a Model of Labor Supply, Fertility, and Wages of Married Women," Journal of Political Economy, 84:Part II, 179-199, (1976).

and Weininger, Adriana

"Economic Determinants of Fertility: Results Using Cross-sectional Aggregate Data," Demography, 10:205-233 (1973).

Conger, Darius J. and Campbell, John M., Jr., "Simultaneity in the Birth Rate Equation: The Effects of Education, Labor Force Participation, Income and Health," Econometrica, 46:631-641 (1978)

DeTray, Dennis N., "Child Quality and the Demand for Children," Journal of Political Economy, 81:Part II, 70-95 (1973).

Esterlin, Richard A., "Towards a Socioeconomic Theory of Fertility: A Survey of Recent Research on Economic Factors in American Fertiligy," in Fertility and Family Planning: A World View. eds. S. J. Behrman, et al. Ann Arbor: The University of Michigan Press, 1969.

Fulmer, John L., "Factors Influencing State Per Capita Income," Southern Economic Journal, 16:259-278 (1950).

Gardner, Bruce, "Economics of the Size of North Carolina Rural Families," Journal of Political Economy, 81:Part II, 99-122 (1972).

Grabill, Wilson H., Kiser, Clyde V. and Whelpton, Pascal K., The Fertility of American Women. New York: John Wiley 1958.

Gregory, Paul R., Campbell, John M. and Cheng, Benjamin, "A Cost-Inclusive Simultaneous Equation Model of Birth Rates," Econometrica, 40:681-687. (1972a).
, "A Simultaneous Equation Model of Birth Rates in the United States," The Review of Economics and Statistics, 54:374-380 (1972b).

Hanna, Frank A., State Income Differentials, 1919-1954. Durham, N.C.: Duke University Press, 1959.

Holmes, R. A. and Munro, J. M., "Regional Nonfarm Income Differences in Canada: An Econometric Study," Journal of Regional Science, 10:65-74 (1970).

Kiser, Clyde V., Grabill, Wilson H. and Campbell, Arthur A., Trends and Variations in Fertility in the United States, Cambridge, Mass.: Harvard University Press, 1968.

Mattila, John M. and Thompson, Wilbur R., "Toward an Econometric Model of Urban Economic Development," in Issues in Urban Economics. eds. H. S. Perloff and L. Wingo, Jr., Baltimore: Johns Hopkins Press, 1968.

Michael, Robert T., "Education and the Derived Demand for Children," Journal of Political Economy, 81:Part II, 128-164 (1973).

Mincer, Jacob, "Market Prices, Opportunity Costs, and Income Effects," in Measurement in Economics. eds. Carl Christ, et al. Stanford, Calif.: Stanford University Press, 1963.

Nerlove, Marc and Schultz, T. Paul. Love and Life Between the Censuses: A Model of Family Decision Making in Puerto Rico, 1950-1960. RM-6322-AID. Santa Monica, Calif.: Rand Corporation, 1970.

Phillips, Llad, Votey, Harold and Maxwell, Harold E., "A Synthesis of the Economic and Demographic Models of Fertility: An Econometric Test," The Review of Economics and Statistics, 51:298-308 (1969).

Schultz, T. Paul, "An Economic Model of Family Planning and Fertility," Journal of Political Economy, 77:153-180 (1969).

Smith-Lovin, Lynn and Tickamyer, Ann R., "Nonrecursive Models of Labor Force Participation, Fertility Behavior and Sex Role Attitudes," American Sociological Review, 43:541-557 (1978).

Tolley, G. S. and Olson, E., "The Interdependence between Income and Education," Journal of Political Economy, 79:460-480 (1971).

U.S. Department of Commerce, Bureau of the Census. State Economic Areas. United States Government Printing Office, 1962 and 1972.

U.S. Department of Labor, Bureau of Labor Statistics. Three Standards of Living for an Urban Family of Four Persons. Spring 1967 and 1970.

Waite, L. J. and Stolzenberg, R. M., "Intended Childbearing and Labor Force Participation of Young Women: Insights from Nonrecursive Models," American Sociological Review, 41:235-251 (1976). 